\title{
A framework for the simplified risk analysis of cultural heritage assets
}

\author{
Xavier Romão ${ }^{\mathrm{a}, *}$, Esmeralda Paupério ${ }^{\mathrm{b}}$, Nuno Pereira ${ }^{\mathrm{a}}$ \\ a CONSTRUCT-LESE, Faculty of Engineering, University of Porto, Porto, Portugal \\ ${ }^{\mathrm{b}}$ Construction Institute, CONSTRUCT-LESE, Faculty of Engineering, University of Porto, Porto, Portugal
}

\section{A R T I C L E I N F O}

\section{Article history:}

Received 29 April 2016

Accepted 12 May 2016

Available online 8 June 2016

\section{Keywords:}

Risk assessment

Vulnerability

Hazard

Built immovable cultural heritage

Cultural heritage value

\begin{abstract}
A B S T R A C T
A simplified risk assessment framework specifically developed for built immovable cultural heritage assets is proposed. The framework addresses all the components in a risk analysis and can be used as a screening procedure for the preliminary assessment of a large number of assets with limited resources. Furthermore, the framework can also be used to identify cultural heritage assets that require a more refined and resource demanding risk evaluation. The proposed risk analysis framework falls into the category of qualitative methods and is based on an existing approach developed for the vulnerability assessment of critical infrastructures. The qualitative risk analysis of the proposed methodology is based on a set of structured assessment flowcharts that address the main components of a risk analysis: the likelihood of the hazard, the vulnerability of the asset to the hazard, the consequences of the hazard, the loss of value of the asset and the capacity to recover from the event. To illustrate the applicability of the proposed methodology, an application example is also presented for the case of seismic risk.
\end{abstract}

(C) 2016 Elsevier Masson SAS. All rights reserved.

\section{Introduction and research aim}

Risk is a concept deeply embedded in the collective consciousness of modern society and there is currently a worldwide trend to enhance our understanding of risks in order to increase our ability to manage them. Although an objective and universal definition of risk is yet to be established [1], it can be seen as a measure of the combined likelihood of occurrence of a threatening event and of its potential consequences. Such threatening events are usually termed hazards and represent a potentially damaging physical event, natural or man-made, that can cause loss of life or injury, property damage, social and economic disruption or environmental degradation [2]. On the other hand, the potential consequences, globally termed as losses, can be seen as the result of existing vulnerabilities (e.g. physical, social, economic or environmental vulnerabilities) that represent the susceptibility to the damaging effects of the hazard [2] combined with a lack of ability to cope with those consequences, i.e. a lack of resilience [3].

Disasters can occur when the probable nature of the hazard becomes a real damaging event and when the potential consequences turn into actual losses. Over the years, several international initiatives have been promoted to address the issues of disaster risk reduction (DRR) and disaster risk management (DRM) in order

\footnotetext{
* Corresponding author. Tel.: +351 22508 1956; fax: +35122508 1835 . E-mail address: xnr@fe.up.pt (X. Romão).
}

to establish new approaches to reduce the impact of disasters in society. The wide-ranging concepts of DRR and DRM involve the development and application of policies, strategies and practices to minimise disaster risks throughout society. In 2005, the adoption of the Hyogo Framework for Action (HFA) 2005-2015 [4] was an important step towards these objectives. The HFA was the first internationally accepted framework where international agencies and national governments have set targets and commitments for DRR which were defined through five priorities for action. Of those five priorities, Priority Action 2 specifically addressed risk assessment and monitoring [4]. Therefore, the HFA clearly acknowledged that the sustainable implementation of disaster mitigation actions can only be achieved when based on adequate knowledge about the hazards threatening relevant assets and their vulnerability to those hazards.

Even though the HFA ended in 2015, efforts towards DRR continue since the HFA has now been replaced by the Sendai Framework for Disaster Risk Reduction 2015-2030 [5]. This new framework is expected to build on the achievements of the HFA to establish a set of improvements. Despite the worldwide progress achieved in DRR with the implementation of the HFA, several features were identified for its enhancement (e.g. see [6-9]). Among other aspects, the importance of cultural heritage and its irreplaceable value for society have been explicitly recognized, thus emphasising the need to assess the impact that potential hazards may have on cultural heritage $[5,6]$. Moreover, the significant role of cultural heritage in social cohesion and sustainable development 
has also been highlighted, making it a key resource to build resilient societies [10].

Despite these concerns, irreplaceable losses of cultural heritage continue to occur throughout the world as a result of natural or man-made disasters (e.g. [11-16]). Even though numerous cultural heritage assets require the implementation of risk mitigation measures (e.g. [17-21]), the development of such measures needs to be based on adequate knowledge about the risks these assets are facing. However, for most countries, carrying out a multi-hazard risk analysis for a large number of cultural heritage assets requires efforts and budgets that are frequently unavailable. Therefore, assessing the risks for a large number of assets with limited resources is only feasible when based on simple methodologies.

To address this need, a methodology developed to perform the qualitative risk assessment of a large number of assets with limited resources is presented herein. The proposed methodology involves all the components in a risk analysis and can be used as a screening procedure for the preliminary assessment and identification of built and immovable cultural heritage assets that require a more refined and resource demanding risk evaluation. Given the general format of the methodology, it is expected to be applicable to any type of cultural heritage asset threatened by any type of hazard. Specific aspects of the framework were further detailed for the particular case of seismic risk and an application to a single cultural heritage property is presented to illustrate these procedures. The results of this example are also correlated with those of a more detailed and complex analysis.

\section{Outlook of existing risk analysis methodologies}

The ideal theoretical setting for conducting a risk analysis requires the probabilistic quantification of hazard, vulnerability and resilience. To establish probabilistic representations of those components, both sufficient/reliable data and adequate analytical/numerical procedures are necessary. However, in many situations, namely in the risk analysis of cultural heritage assets, defining these components in a reliable probabilistic context can be far too complex or resource demanding.

In terms of the hazard, its probabilistic representation can usually be achieved based on data from past events. Typically, for natural events such as earthquakes, floods, landslides or volcanic eruptions, a probabilistic hazard can be defined, e.g. see [22-25]. However, there are fields for which establishing a probabilistic hazard is still complex mostly due to a lack of adequate data [26-28]. For the case of vulnerability, its definition relies on the availability of procedures capable of forecasting the damaging/negative effects that a particular hazard may have on a certain asset under analysis. Although detailed vulnerability representations can be established in several contexts, e.g. [29,30], for the particular case of cultural heritage assets, their complexity and the lack of knowledge regarding their behaviour in certain situations are often important obstacles to the detailed definition of their vulnerability [31,32]. Furthermore, when the risk analysis addresses a large amount of assets, those difficulties are amplified due to resource-related restrictions that might also come into play. In such cases, vulnerability analyses often involve methodologies where simplified assumptions are made, e.g. see [33-37].

With respect to the resilience component, even though frameworks and quantitative approaches have been developed in some fields, e.g. [38-44] and references therein, methodologies addressing specific aspects related to the preservation of cultural heritage assets are still largely unavailable. In this particular case, disaster prevention with the purpose of coping with the consequences of disasters is commonly addressed by pre-event measures such as implementing education and training programmes in emergency/recovery procedures. Additional predictors of resilience measuring the expected time and resources needed to restore the functionality/quality of the asset [38] could potentially also be established. However, when dealing with cultural heritage assets, the multidimensional nature of the value of the asset and the complexity of its evaluation [45-48] are a major conceptual obstacle. Therefore, in such cases, predicting the time and resources that might be required to restore functionality and quality is much more difficult.

Based on these descriptions, the applicability of a framework that involves a comprehensive risk assessment procedure and the regular update of its results over time needs to integrate the following key issues:

(1) reliable and sufficient data to establish suitable hazard models;

(2) sufficient and reliable data on the assets under risk;

(3) suitable procedures to model the vulnerability;

(4) adequate models to predict the multidimensional consequences of the hazardous event;

(5) sufficient human, time and economic resources.

In the context of a risk assessment procedure for cultural heritage assets, 4 is the most difficult issue to address, regardless of the hazard involved. Furthermore, addressing 1, 2 and 3 successfully can be seen to depend on the availability of 5 . In most cases, these resources will set the boundaries of the scope and comprehensiveness of a risk analysis and will be also fundamental for the successful regular update and monitoring of the risk assessment results over time. Therefore, when dealing with a large number of cultural heritage assets, it is important to have a simple methodology that can be used for the preliminary risk analysis of those assets to establish risk mitigation priorities or to identify assets requiring more detailed and resource-demanding analyses.

Based on these arguments, it can be seen that a qualitative risk analysis approach can fulfill the necessary requirements. In a qualitative risk method, risk is defined by a non-numerical estimate. Even though qualitative analyses still involve analytical and evidence-based characterizations of the risk, they establish descriptive or categorical treatments of information instead of numerical estimates. These methods simplify the risk analysis by reducing the required inputs and calculations to a set of judgments. The simple risk categories that are produced as outputs can then be communicated to policymakers and stakeholders in a simpler way [49]. Qualitative analyses are useful in situations where theory, data, time or expertise are limited but they also provide adequate results when decision makers only need a qualitative assessment of the risk. Furthermore, they can also be useful for problems where quantitative risk analysis is impractical. For example, the qualitative analysis of a large number of cultural heritage assets (e.g. nationwide) may be a suitable way to identify situations where a more detailed assessment is needed [50]. Qualitative methods may also be preferred when the more important sources of uncertainty will not change the end result or when quantitative analysis is likely to lead to inconclusive results [51]. In many situations, a qualitative risk analysis is able to provide risk managers or stakeholders with enough information for decision-making. For example, the gathered data may include sufficient evidence indicating that a given risk can, in fact, be disregarded. On the contrary, the gathered evidence may also point out to an unacceptably large risk, or to the fact that consequences of a given hazard are so unacceptable that mitigation measures are needed whatever the level of risk. 


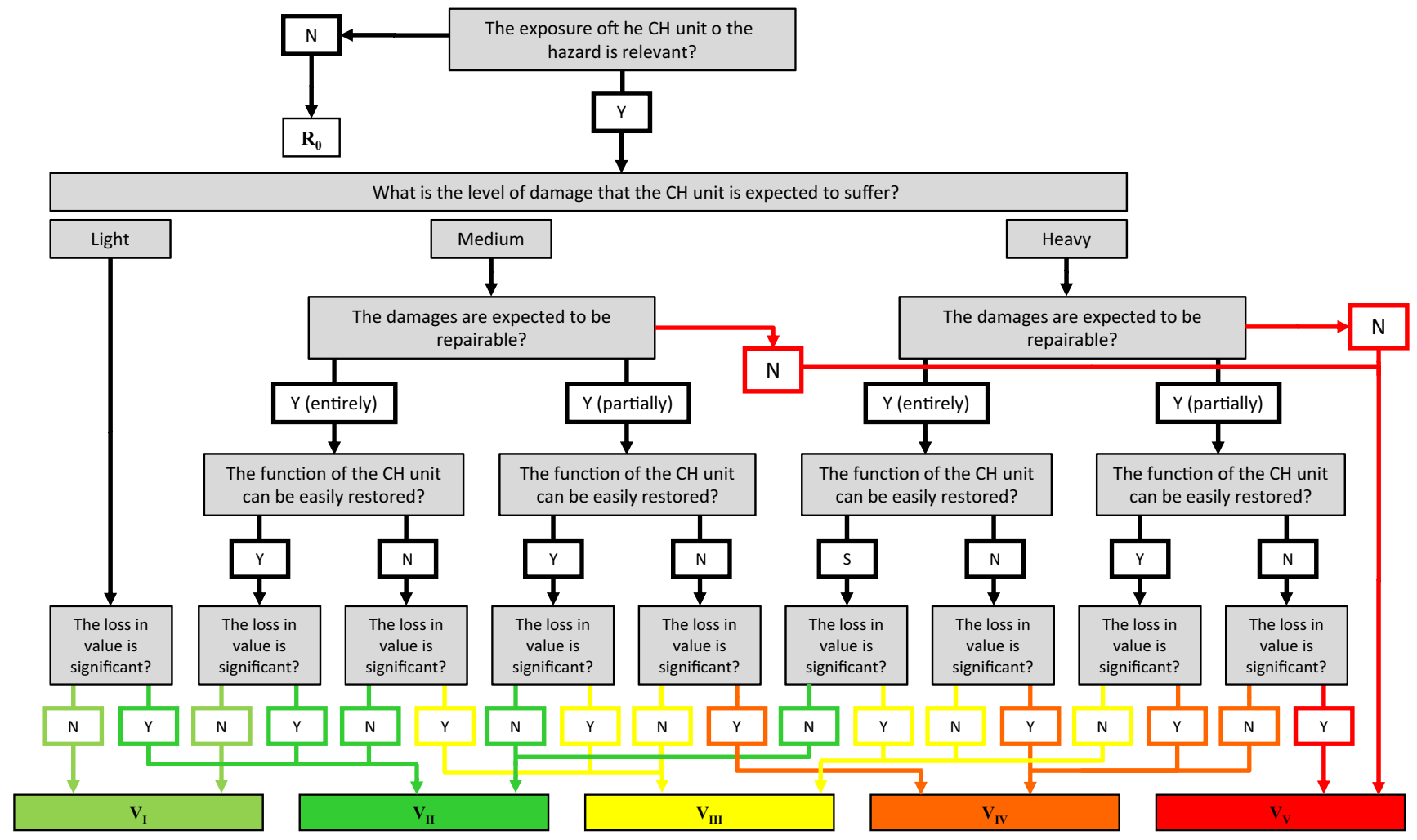

Fig. 1. Proposed risk analysis methodology: assessment of the level of vulnerability of the cultural heritage $(\mathrm{CH})$ unit.

\section{Methodology: a framework for the simplified risk analysis of cultural heritage assets}

\subsection{General overview of the framework}

Based on the arguments in the previous section, a simplified methodology is proposed herein which can be used as a screening procedure for the preliminary risk analysis of built and immovable cultural heritage units. A cultural heritage unit is considered to be a single property or a component that is part of a property for which a risk analysis is required (e.g. a church is a unit but the bell tower of a church may also be considered to be a unit if necessary). The proposed risk analysis framework falls into the category of qualitative methods and is based on an existing approach developed for the vulnerability assessment of critical infrastructures $[52,53]$. The qualitative risk analysis of the proposed methodology is based on a set of structured assessment flowcharts that address the main components of a risk analysis: the likelihood of the hazard, the vulnerability of the asset to the hazard, the consequences of the hazard, and the capacity to recover from the event. Figs. 1 and 2 illustrate the full scope of the flowcharts and outcomes that can be obtained with the proposed framework. Fig. 1 presents the part of the method that establishes the vulnerability of the cultural heritage unit and Fig. 2 presents the part where the vulnerability is combined with the hazard to determine the risk level. As can be seen, the process of Fig. 1 establishes five classes of increasing

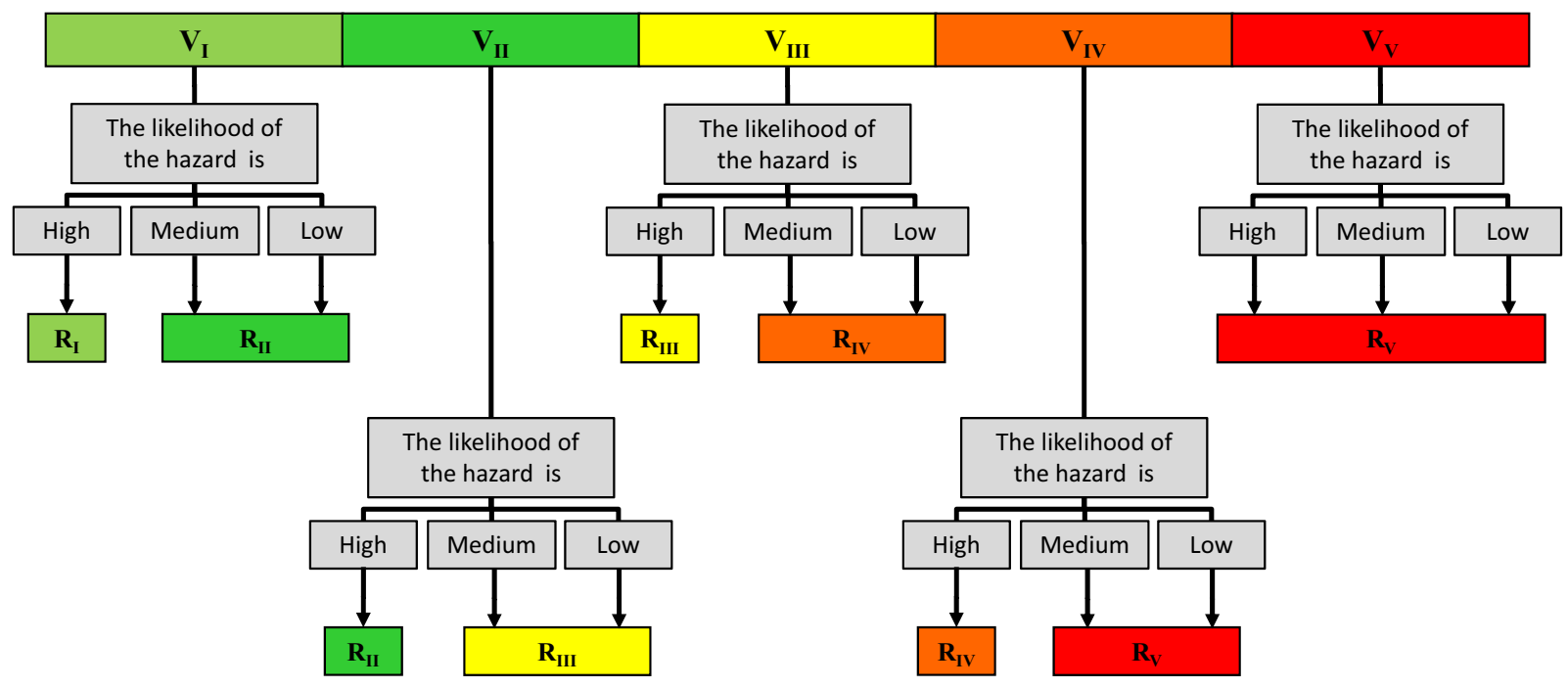

Fig. 2. Proposed risk analysis methodology: assessment of the level of risk of the cultural heritage (CH) unit. 
vulnerability ( $\mathrm{V}_{\mathrm{I}}$ to $\mathrm{V}_{\mathrm{V}}$ ) which are defined by answering questions that address the different components contributing to the vulnerability. It is noted that the process also accounts for the case where a certain cultural heritage unit may have an irrelevant level of risk $\left(R_{0}\right)$ if its level of exposure to the hazard under consideration is not relevant. The process of Fig. 2 can be seen to establish five classes of increasing risk $\left(R_{I}\right.$ to $\left.R_{V}\right)$ based on the vulnerability classes defined by the process of Fig. $1, V_{I}$ to $V_{V}$, and on the expected likelihood of the hazard. The proposed framework considers three categories of expected hazard likelihood which are termed high, medium and low. These hazard categories depend on the type of hazard but must reflect the fact that an event with a high likelihood is expected to have a lower hazard intensity while a low likelihood event is expected to have a higher hazard intensity. For example, for the case of earthquakes, a high likelihood event is expected to have a lower average return period and also a lower magnitude, while for a low likelihood event it is the opposite. The level of hazard likelihood can be based, for example, on the value or range of the average return period of a given hazard scenario or based on available historical hazard scenarios. From Fig. 2 it can be seen that, for a given vulnerability level, when the expected likelihood of the hazard is high or medium, the subsequent risk level is the same. This conservative approach was considered in order to reduce the number of risk categories that result from the proposed framework. Furthermore, it can also be seen that when the vulnerability level is $V_{V}$, the subsequent risk level is always $R_{V}$, irrespective of the expected likelihood of the hazard. In this case, the framework assumes that if a cultural heritage unit exhibits the highest level of vulnerability, the severity of this condition implies the need to also consider the highest level of risk. With respect to the interpretation of these risk levels, although the colour code assigned to each level provides a visual aid, they can be interpreted as follows:

- levels $\mathrm{R}_{\mathrm{I}}$ and $\mathrm{R}_{\mathrm{II}}$ correspond to cases where the level of risk can be accepted;

- level $\mathrm{R}_{\mathrm{II}}$ corresponds to a case where the level of risk is at the limit of acceptability and should be monitored regularly. Given the qualitative nature of the assessment framework and the uncertainties it may involve, a more detailed analysis of the cultural heritage unit should be carried out to determine if the actual risk is not higher;

- level $\mathrm{R}_{\mathrm{IV}}$ corresponds to a case where the level of risk is unacceptable. A more detailed analysis of the cultural heritage unit should be carried out to define risk mitigation measures;

- level $R_{V}$ corresponds to a case where the level of risk is unacceptable and needs to be addressed as soon as possible. A more detailed analysis of the cultural heritage unit is urgently needed to define risk mitigation measures.

Based on the characteristics of the proposed framework, this methodology is believed to be applicable to any type of cultural heritage unit threatened by any type of hazard and can be used to carry out a structured qualitative risk analysis. The application of the procedure starts by defining the hazard scenario for which the risk analysis of a certain cultural heritage unit is required. After defining this scenario, the analyst will then go through the assessment flowchart of Fig. 1 to establish the vulnerability level. The assessment flowchart of Fig. 2 is then used to combine the vulnerability level with the likelihood of the hazard scenario initially defined and obtain the risk level. To provide further guidance for the application of the proposed framework, additional aspects that need to be considered when analysing the components leading to the vulnerability classification are addressed in the following.

\subsection{Characterization of the vulnerability analysis components}

After defining the hazard scenario and establishing that the exposure of the cultural heritage unit to that scenario is relevant, the next step of the vulnerability assessment involves classifying the expected level of damage of the cultural heritage unit for that scenario. This expected level of damage needs to be defined according to one of three possible classes: light, medium or heavy. The following descriptions of those classes can be used as a reference:

- light damage corresponds to the case where the cultural heritage unit only exhibits non structural damage (i.e. damage that will not affect the resisting system and the overall stability of the cultural heritage unit);

- medium damage corresponds to the case where the cultural heritage unit exhibits more severe non structural damage and also suffers moderate structural damage (i.e. damage that will affect the resisting system of the cultural heritage unit without compromising its overall stability);

- heavy damage corresponds to the case where the cultural heritage unit exhibits severe structural damage that can make it unstable (i.e. the overall stability of the cultural heritage unit is compromised) or that can cause the partial or total collapse of the cultural heritage unit.

Given the qualitative nature of the proposed framework, the expected level of damage of a given cultural heritage unit can be estimated using a simplified procedure such as expert elicitation (e.g. see [54-56]) or an indicator-based approach. For the cases of earthquake, flood, fire, hydro-meteorological, landslide and storm hazards, the procedures and data found in [57-70,33] can be used to define simplified indicator-based approaches suitable to estimate the expected level of damage. For the particular case of earthquake hazard, the authors have developed a set of simplified indicator - and mechanics - based procedures for specific types of cultural heritage units [71]. Additional details of these approaches are addressed in the following sections.

In case there are heritage assets attached to the main cultural heritage unit (e.g. tiles, mural paintings, etc.), the vulnerability analysis of the cultural heritage unit should also account for these elements. This influence is, however, only accounted for in the subsequent stages of the vulnerability analysis, even though the damages to these attached heritage assets and those of the cultural heritage unit are correlated. The proposed framework assumes that if light damage is expected in the cultural heritage unit, the damages to the attached cultural assets will be either negligible or fully restorable. As such, only the potential loss of value is analysed in this case (Fig. 1). If the expected damage is medium or heavy, the classification of the following stages of the vulnerability analysis will need to consider the damage and loss in value to both the cultural heritage unit and the attached heritage assets.

For the cases where the level of damage is expected to be medium or heavy, the next component of the framework analyses if those damages are repairable (fully or partially) to determine if it will be possible to reuse the cultural heritage unit as before the occurrence of the damaging event. Damages are considered to be repairable if it is physically and technically possible to restore the physical and material integrity of the cultural heritage unit. In this context, the following repair possibilities should be examined:

- restoring the materials to their initial conditions without compromising the authenticity of a cultural heritage unit (which may be connected to its value); 
- stabilizing the damaged elements without masking or hiding the results of the repair, strengthening, reconstruction or consolidation process carried out in the cultural heritage unit.

Since the expected level of damage was defined in terms of structural and non structural damage, the reparability analysis must be carried out separately for these two types of damages. Furthermore, if there are heritage assets attached to the main cultural heritage unit, this analysis must also account for these elements. As before, expert elicitation and judgement based on the characteristics of the cultural heritage unit under analysis is expected to be instrumental to assess the expected damage reparability.

After classifying the possibility of repairing the expected damage, the framework then analyses how easy will it be to restore the function of the cultural heritage unit back to its pre-damaging event state (even if only partially). According to the proposed framework, this stage of the analysis is expected to reflect and characterize the resilience of the cultural heritage unit. To perform this classification, the time, human and financial resources necessary to repair and/or stabilize the damages need to be analysed. In addition, resources that may be required to restore and/or develop the human and technical means necessary for the activities associated to the function of the cultural heritage unit must also be accounted for. In this context, it is noted that the ability to restore the predamaging event function may depend on factors other than those directly related to the cultural heritage unit. For example, factors related to heritage assets that may be attached to the main cultural heritage unit (e.g. tiles, mural paintings, etc.) or movable heritage assets (e.g. museum collections) that may be inside the main cultural heritage unit should be considered in this stage if they are found to be relevant to its function. As for the previous stages, expert elicitation and judgement are expected to be instrumental to classify this stage. As a suggestion, if the availability of human and financial resources is not a restriction, the function of the cultural heritage unit can be considered to be easily restored if it occurs up to 6 months after the end of the post-event emergency response operations.

Finally, the last stage of the vulnerability assessment analyses the significance of the expected loss in value of the cultural heritage unit. Given the simplified nature of the proposed vulnerability assessment process and the well-known difficulties in defining the multiple dimensions of cultural heritage value, the loss of value analysis must also be based on simple qualitative principles. In this analysis, it is suggested that the following five types of value, which are partially based on [72], should be considered to analyse the expected loss of value of a certain cultural heritage unit:

- evidential value: it derives from the potential of the cultural heritage unit to yield evidence about past human activity (physical remains, written records, archaeological deposits, etc.);

- historical value: it derives from the ways in which past people, events and aspects of life can be connected through the cultural heritage unit to the present (it can be divided into (a) illustrative value: the extent to which it illustrates something particular or distinctive; (b) associative value: the extent to which it is associated with a notable family, person, event or movement);

- aesthetic value: it derives from the ways in which people draw sensory and intellectual stimulation from the cultural heritage unit (either as a result of conscious design or the seemingly fortuitous outcome of the way in which the cultural heritage unit has evolved and has been used over time);

- communal value: it derives from the meanings of the cultural heritage unit for the people who relate to it, or for whom it figures in their collective experience or memory (these can include (a) commemorative and symbolic values: the meanings of a place for those who draw part of their identity from it, or have emotional links to it; (b) social value: places that people perceive as a source of identity, distinctiveness, social interaction and coherence; and (c) spiritual value: emanate from the beliefs and teachings of an organised religion, or reflect past or present-day perceptions of the spirit of place);

- economic value: it derives from the potential of the cultural heritage unit to produce financial dividends for society as a result of direct or indirect economic activities connected to the use and function of the cultural heritage unit.

The expected loss in value can be connected to more than one class, depending on the type of cultural heritage unit under consideration. Therefore, the analysis of the expected loss in value should consider the relative importance of each of the five classes of value, which needs to be defined case by case. In general, the expected loss of value will depend on the expected level of damage as well as on the possibility of repairing such damage. In some cases, the expected loss of value will also need to consider how easy it is to restore the function of the cultural heritage unit since this factor may be particularly relevant for the loss of economic value. Furthermore, it is also noted that the uniqueness and rareness of a given cultural heritage unit should be reflected in the expected loss of value analysis and it may be associated with any of the referred classes of value. As for the previous stages, expert elicitation and judgement is expected to be instrumental to classify this stage. As for the previous stages, if there are heritage assets attached to the main cultural heritage unit, their contribution to the loss in value should also be accounted for. However, it is noted that this analysis does not include potential losses to movable heritage assets that may be inside the main cultural heritage unit. In relevant cases, a separate analysis of the expected loss of value to these heritage assets should be performed using a suitable methodology.

\section{Detailing of the framework for earthquake risk analysis}

As previously referred, the presented risk analysis framework was further developed for the particular case of earthquake hazard. Given that different types of constructions exhibit different behaviours under earthquakes, cultural heritage units need first to be assigned to architectural classes reflecting those differences. Based on these classes, analysis procedures can then be defined for each class which account for their specific behaviour under earthquakes. In the context of seismic analysis, a general classification of cultural heritage units has been defined in [73] that proposes six classes accounting for the construction morphology and the building technology. Since the detailing of the proposed framework for earthquake risk analysis was not developed for all types of constructions, a classification is proposed herein establishing only four architectural classes (CA1 to CA4) partially based on [73]. The architectural classes considered herein only involve masonry constructions and a different method was defined for each class to analyse the expected level of earthquake damage. The architectural classes that were considered are described in Table 1 and Figs. 3-6 present a few examples of cultural heritage units of each class.

For each type of architectural class, simplified indicator - and mechanics - based procedures were developed to establish the

Table 1

Architectural classes of masonry constructions considered in the proposed framework.

\begin{tabular}{ll}
\hline Architectural class & Description \\
\hline CA1 & Single-storey or multi-storey masonry building \\
CA2 & Hollow slender masonry construction \\
CA3 & Solid slender masonry construction \\
CA4 & Arched masonry construction \\
\hline
\end{tabular}



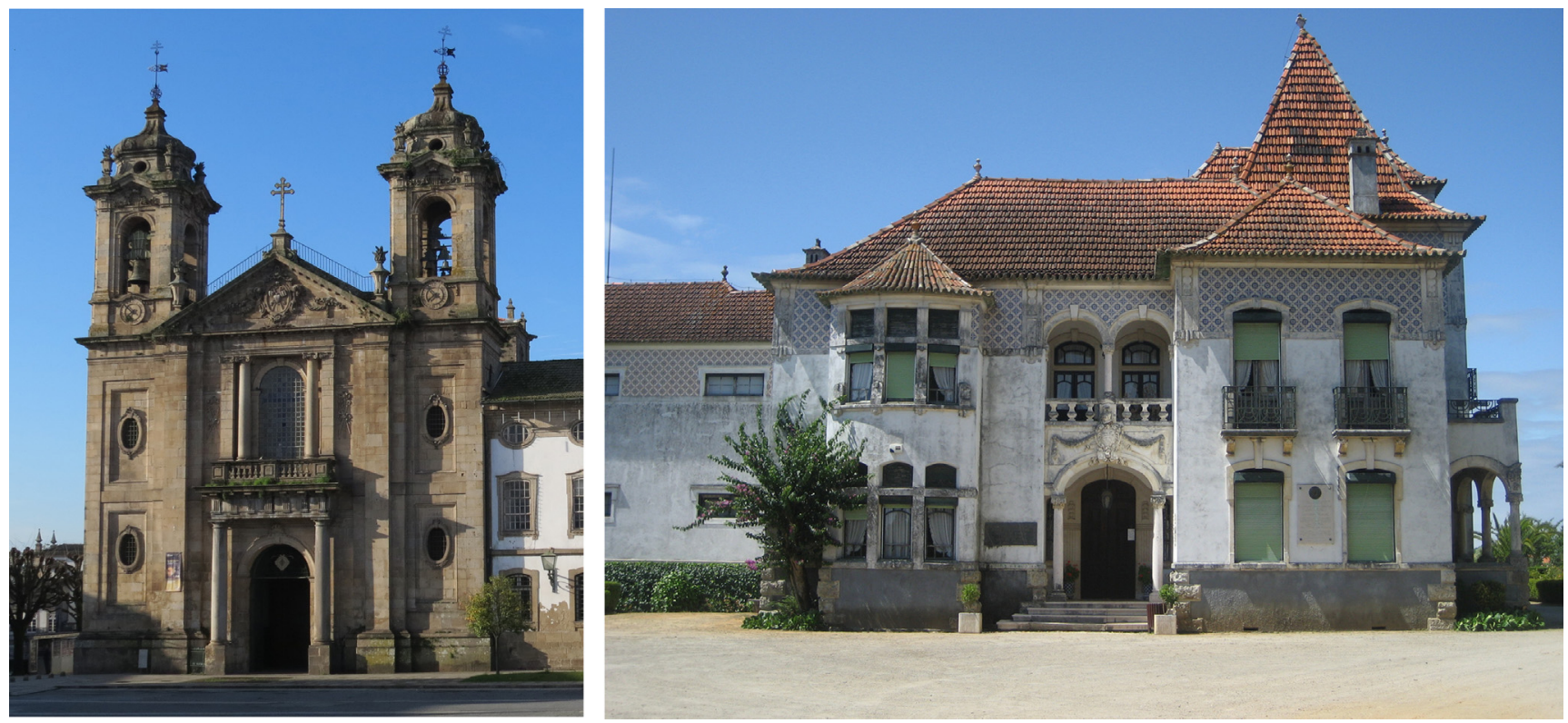

Fig. 3. Examples of constructions from the architectural class CA1.

expected level of damage under a given scenario of earthquake occurrence. These procedures are based on the classification of several parameters related, for example, to the geometry and shape of the cultural heritage unit, to its integration with the surrounding environment, to the type of structural system, to the quality of the materials, and to its state of conservation. For each architectural class, a specific data form and manual were developed to record all the necessary parameters and determine the expected level of damage. The detailed description and definition of the data forms and manuals developed for the four architectural classes are presented in [71] but are unable to be reproduced herein for the sake of brevity. However, it is referred that the procedure developed for cultural heritage units of class CA1 is based on the classification and weighted average of 14 parameters related to the type of structural system, the characteristics of the masonry, the lateral strength of the structure, geometric factors such as the maximum distance between walls and the height of the building, the type of foundations and soil conditions, the building position and interaction with respect to its surroundings, plan and vertical regularity factors, the type and arrangement of openings, the type of floor system, the type of roof system, the state of conservation of the structural system and the existence of non-structural falling hazards [59,69,74-77]. The weighted average of these parameters leads to the quantification of a fragility index which is then correlated with the level of
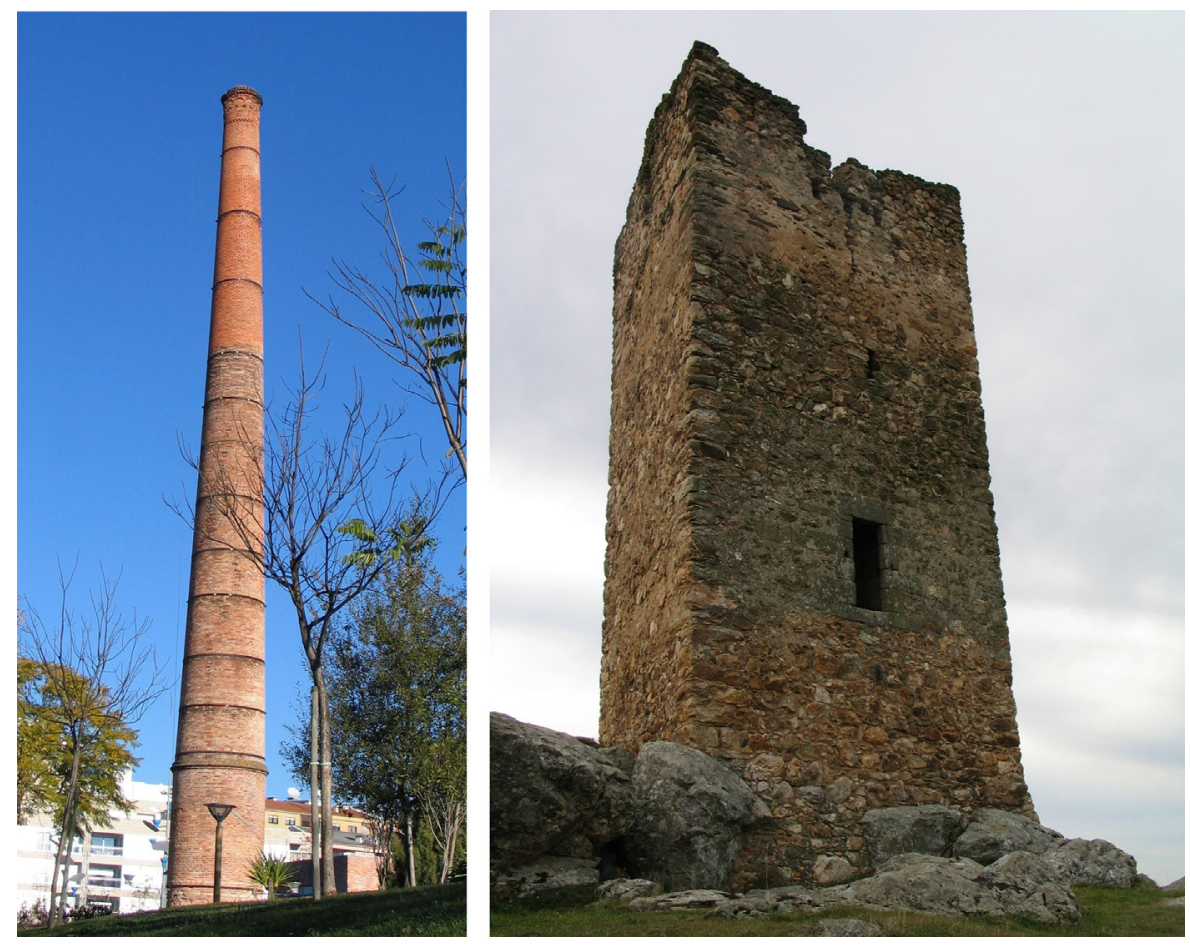

Fig. 4. Examples of constructions from the architectural class CA2. 

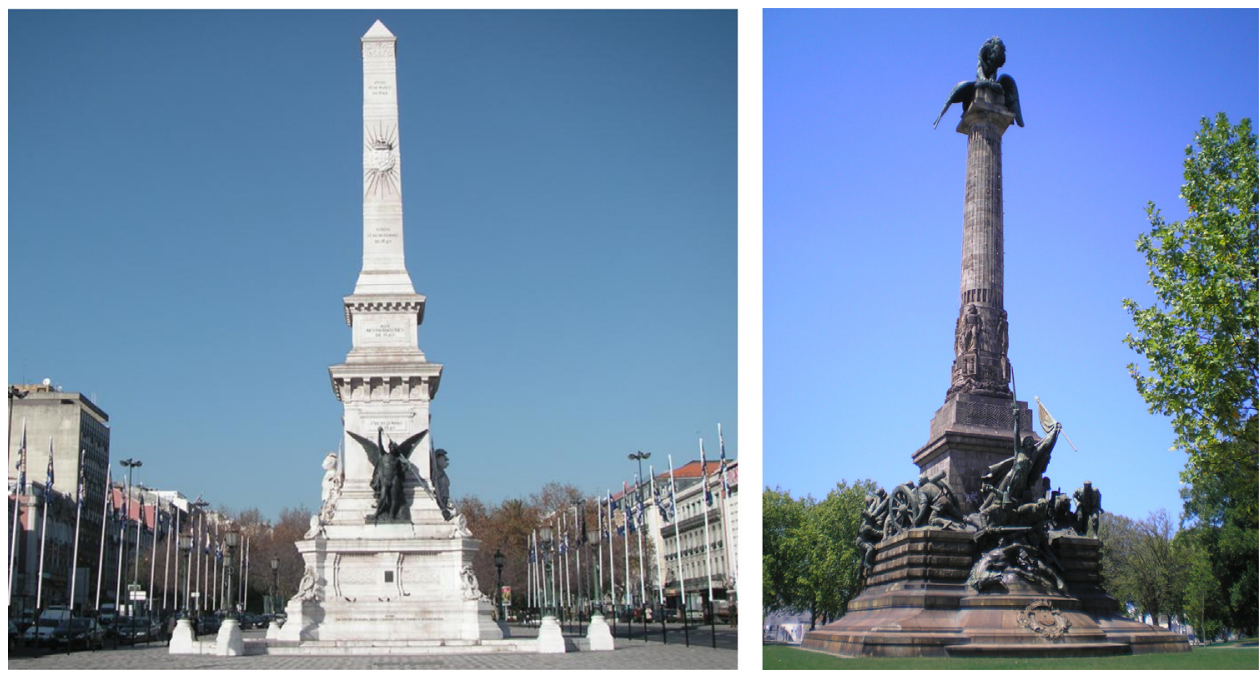

Fig. 5. Examples of constructions from the architectural class CA3.

expected damage. The procedure developed for cultural heritage units of class CA2 is similar to that of class CA1. For class CA2, the procedure is based on the classification and weighted average of 12 parameters related to the type of structural system, the characteristics of the masonry, the lateral strength of the structure, the slenderness of the structure, the type of foundations and soil conditions, the construction position and interaction with respect to its surroundings, plan and vertical regularity factors, the type and arrangement of openings, the type of floor and roof systems, the state of conservation of the structural system and the existence of non-structural falling hazards [78-81]. The procedures developed for cultural heritage units of classes CA3 and CA4 are different than those of classes CA1 and CA2 since they are mostly based on simple mechanics-based approaches. For class CA3, the expected level of damage is determined from the overturning stability of the construction and its sensitivity to develop a rocking mechanism. In this case, the procedure depends on the geometric and material properties of the construction, the type of foundations and soil conditions, the dynamic properties and the slenderness of the construction [82-88]. For class CA4, the expected level of damage is determined by analysing the stability of single or multiple arch systems with respect to transversal failure mechanisms. The procedure depends on the geometric characteristics of the structure (i.e. single or multiple arch system, type of pier, type of abutment, dimensions), the out-of-plane strength of the spandrel wall, the out-of-plane global arch-piers strength and the soil conditions [89-92].

Since the data required for each form needs to be obtained from existing documentation and in situ surveys, the level of reliability of the data that is considered is also established in the form. For cultural heritage units of classes CA1 and CA2, each parameter required to define the expected level of damage is assigned with a reliability level $(0,0.25,0.50,0.75$ and 1.0 for low to high reliability levels) which reflects the uncertainty in the value of each parameter. A global reliability level of the damage analysis is then obtained from the weighted average of the individual values. If the global reliability level is below 0.20 , the damage analysis is not valid and more reliable data is required. If the global reliability level is between 0.20 and 0.50 , the damage analysis is accepted but obtaining additional information on the more uncertain parameters is recommended. If the global reliability level is higher than 0.50 , the damage analysis is fully accepted. For cultural heritage units of classes CA3 and CA4, the global reliability level is established directly in a qualitative way since the number of parameters that are needed is much lower. For these classes, Low, Medium and High levels of reliability are qualitatively defined for the damage analysis that are in agreement with the three numerical ranges defined for classes CA1 and CA2.
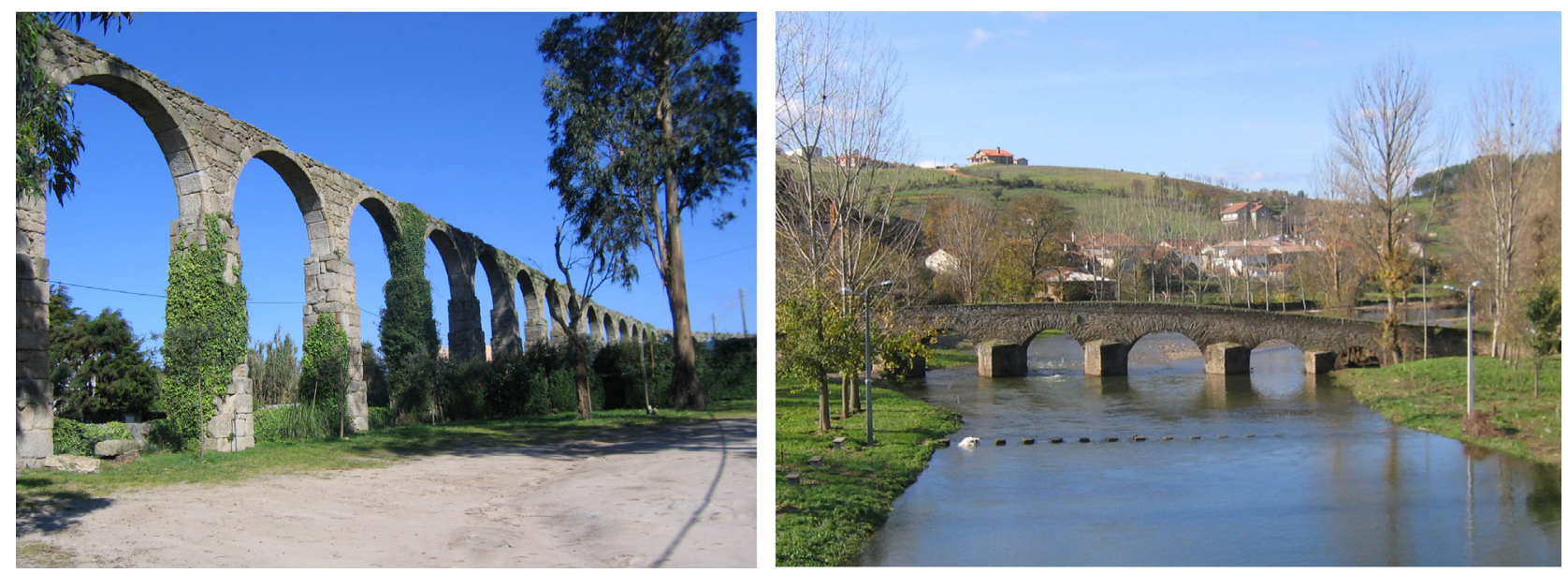

Fig. 6. Examples of constructions from the architectural class CA4. 


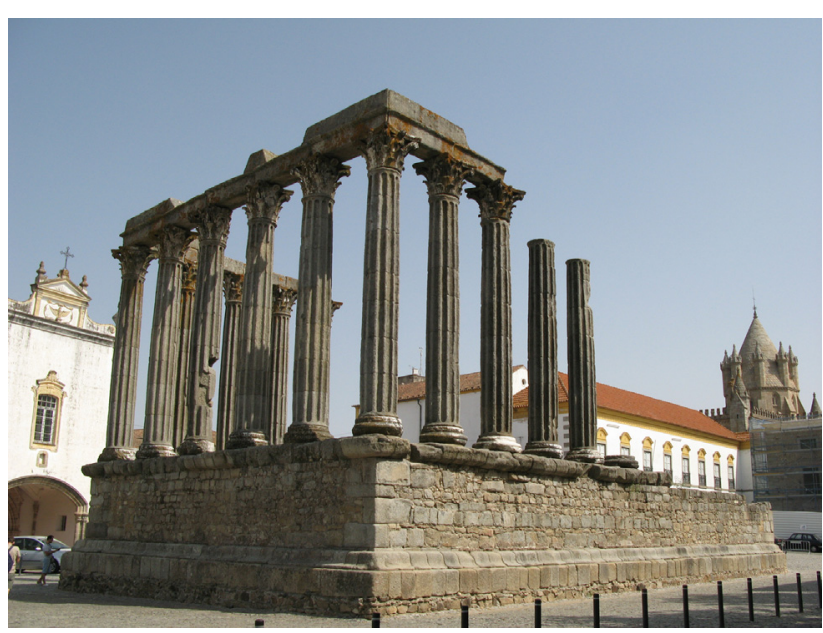

Fig. 7. View of the current condition of the Roman Temple of Évora [93].

\section{Application of the framework to analyse the seismic risk of the Roman Temple of Évora}

To illustrate the applicability of the proposed framework, the seismic risk assessment of the Roman Temple of Évora, in Portugal, is presented as a case study. For the purpose of determining the level of expected damage, the Roman Temple of Évora was considered to be a cultural heritage unit from the architectural class CA3, as shown in the following. To provide further details about this case study application, the procedure leading to the level of expected damage is also described next.

\subsection{Description of the Roman Temple of Évora}

The Roman Temple of Évora (Fig. 7) is located in the UNESCO World Heritage Site of the historical centre of Évora, Portugal. The exact time of construction of the temple is not known exactly but the stylistic characteristics of the capitals indicate it likely dates back from the time of Roman emperor Augustus [94]. Even though the temple construction is likely to have begun in the 1st century $\mathrm{AD}$, the construction was only finished between the 2nd and 3rd centuries [94]. Over time, the temple structure has undergone several modifications and reconstructions (see Fig. 8). The temple is believed to have been destroyed around the 5th century during the Visigoth invasion and additional writings indicate the temple was integrated in the Évora castle in the 14th century, serving simultaneously as a fortified house and as a slaughterhouse [94]. In 1836, the temple stopped being used as slaughterhouse and became the focus of a large archaeological intervention that would eventually lead to the temple's present configuration [94].
Currently, the structure of the temple has fourteen Corinthian columns exhibiting different levels of damage, configurations and heights. Two of these columns are free standing while the remaining ones are connected by an architrave superimposed on the top of the columns. The architrave blocks and the column shaft drums are made of granite while the base blocks and capitals of the columns are made of marble [95]. Recent studies [96] have shown that the marble blocks of the architrave are connected to each other by iron connectors. On the other hand, no connections were found between the drums of the columns. The total height of the colonnade columns (i.e. the height of the base, shaft and capital) is $7.7 \mathrm{~m}$ while that of the freestanding columns is only 6.7 since they are missing the capitals [97]. The shaft of each column has a diameter of approximately $0.90 \mathrm{~m}$ [97]. All the columns are spaced $2.25 \mathrm{~m}$ apart and sit on a plinth with an area of $15 \times 25 \mathrm{~m}^{2}$ and a height that varies between of $3.5 \mathrm{~m}$ and $4.3 \mathrm{~m}$ [97]. The height of the architrave varies across the temple and it is made of one or two layers of granite blocks, where each block can be assumed to have a height of $0.60 \mathrm{~m}$ and a width of $0.90 \mathrm{~m}$. A specific mass of $2625 \mathrm{~kg} / \mathrm{m}^{3}$ was considered for the granite blocks while for the marble blocks the considered specific mass was $2563 \mathrm{~kg} / \mathrm{m}^{3}$ [98].

All the elements of the temple exhibit some level of damage. The most severe damage can be found in the two middle columns from the main façade of the temple. The bases and drums of these columns were cut to give room for a doorway that was possibly needed when the temple was serving as a slaughterhouse [97]. Many of the marble base blocks also exhibit damages which range from erosion and chipping of small pieces of stone to complete separation of the blocks into two pieces. The marble capitals and several drums of the columns (other than the two columns previously referred) also exhibit loss of material in some places. It was also seen that most of the elements of the temple exhibit biodeterioration from lichen, algae or moss [97]. For further details regarding the characteristics, existing damage and dynamic properties of the temple, readers are referred to [97,99].

In order to analyse the seismic risk according to the framework previously presented, the temple was considered to be a construction from architectural class CA3 since the structural stability is controlled mainly by the stone columns. Given the current geometric configuration of the temple, the structure was divided into four structural systems and a separate damage analysis was performed for each one (Fig. 9). The seismic vulnerability and risk of the temple were then considered to be governed by the structural system where the level of damage is expected to be higher. System 1 is a group of three columns along the longitudinal direction of the temple topped by the architrave which is mostly made of two layers of granite blocks. System 2 is a group of five columns along the longitudinal direction of the temple also topped by the architrave which, in this case, is mostly made of only one layer of blocks. System 3 is a group of six columns along the transverse direction of the temple also topped by the architrave which is mostly made of
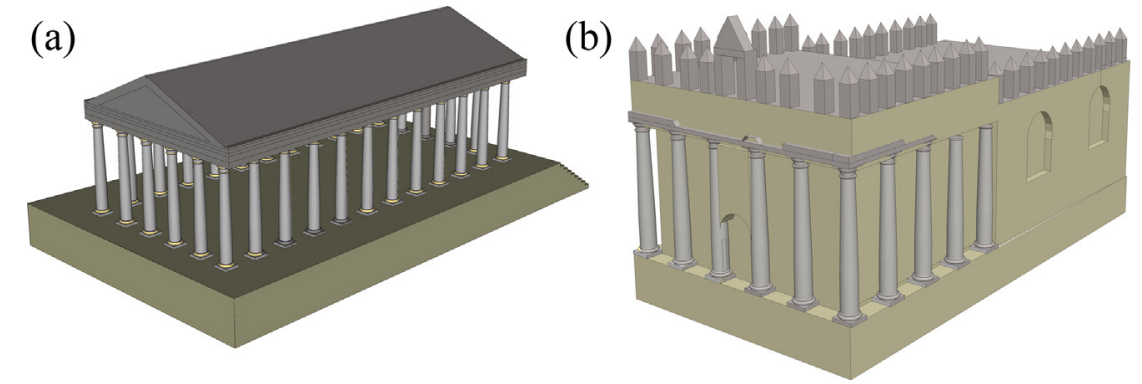

(c)

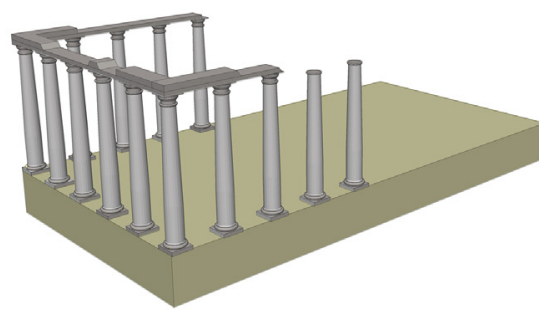

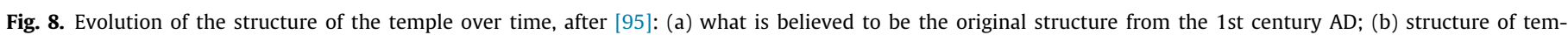
ple/slaughterhouse at the beginning of the $19^{\text {th }}$ century; (c) current structure. 


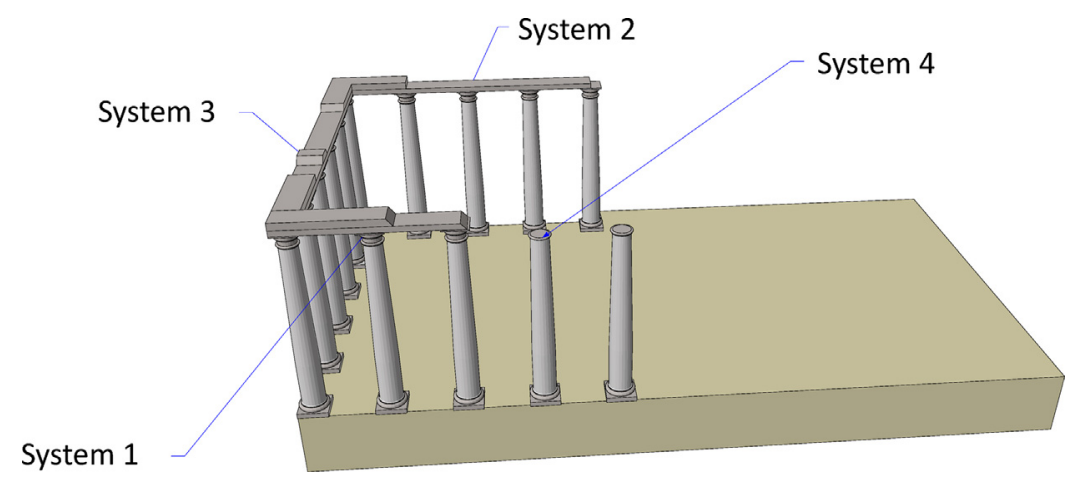

Fig. 9. Structural systems considered for the damage analysis of the temple.
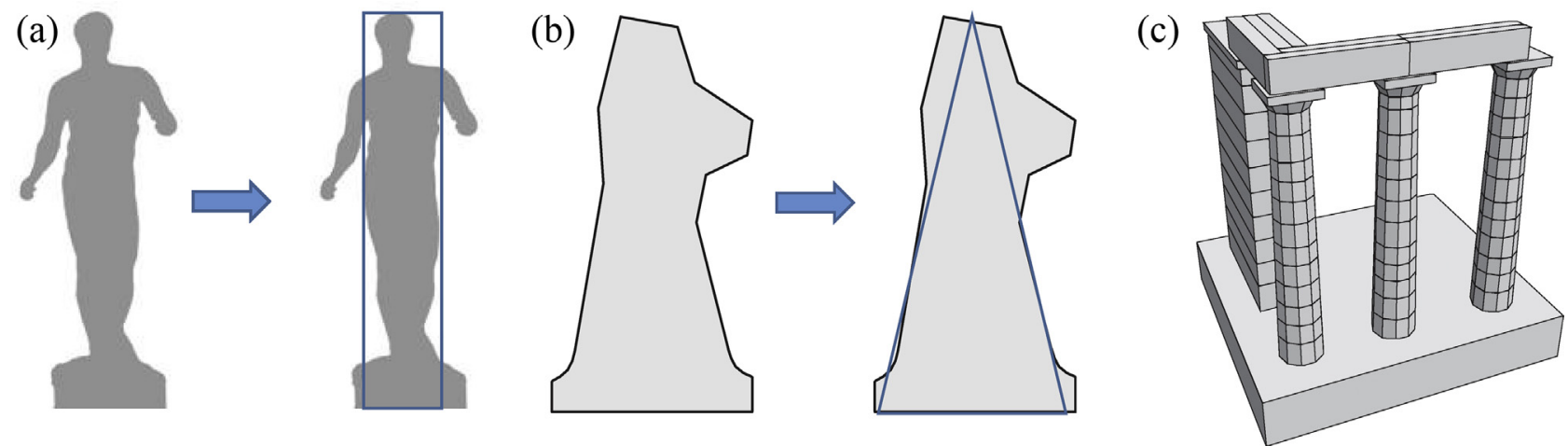

Fig. 10. Schematic representation of Type I (a), Type II (b) and Type III (c) constructions belonging to architectural class CA3 (adapted from [100]).

only one layer of blocks. Finally, System 4 refers to the freestanding columns.

\subsection{Determining the expected level of damage for constructions of architectural class CA3}

According to the procedure detailed in [71], constructions belonging to architectural class CA3 can be of three types. Constructions of Type I involve cases where the construction can be analysed using a single rectangular block, Fig. $10 \mathrm{a}$ ), and require the geometric parameters represented in Fig. 11 a). Constructions of Type II involve cases where the construction can be analysed using a single block with a variable geometry in elevation according to Fig. $10 \mathrm{~b}$ ), requiring the geometric parameters represented in Fig. 11 b). Constructions of Type III involve multi-column structures topped by an architrave providing a connection between the several elements, Fig. $10 \mathrm{c}$ ). For this type of construction, all the columns are assumed to have the same geometry and the necessary parameters for this case are those represented in Fig. 11 c). For constructions of Type III, an additional parameter $\zeta$ defined by eq. (a)

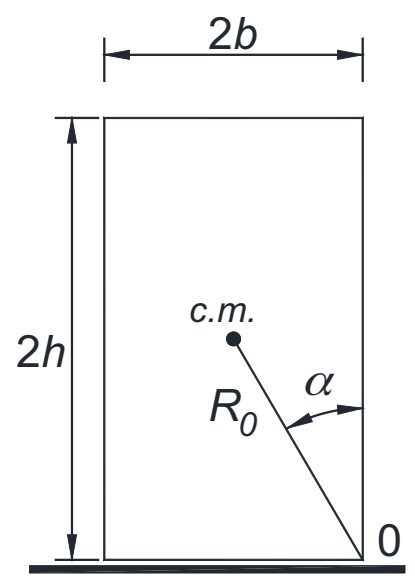

(b)

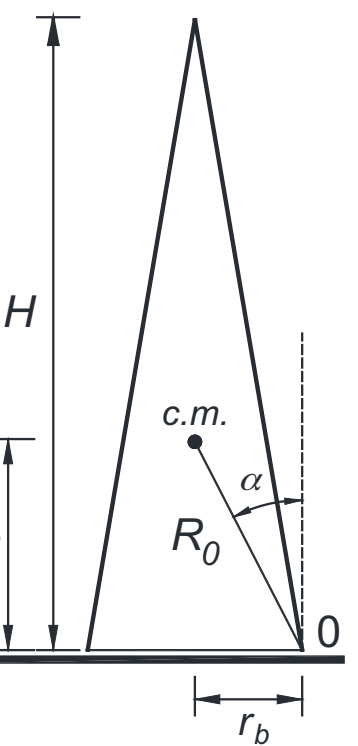

(c)

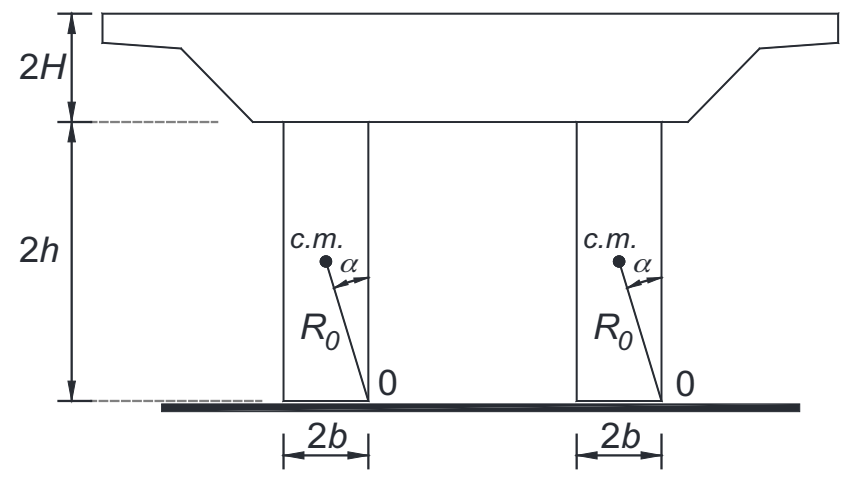

Fig. 11. Geometric parameters of Type I (a), Type II (b) and Type III (c) constructions belonging to architectural class CA3 (c.m. is the centre of mass of the element). 


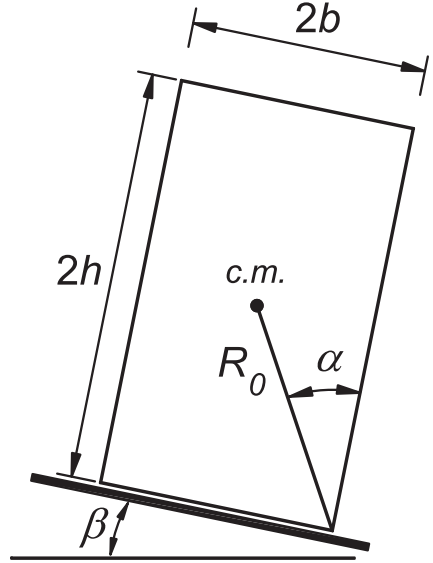

Fig. 12. Schematic representation of a Type I construction with a sloped foundation.

(1) as the ratio between the mass of the architrave and the mass of the columns is also necessary.

$\zeta=$ mass $_{\text {architrave }} /$ mass $_{\text {columns }}$

The slope angle $\beta$ of the foundation is also accounted for in this analysis, Fig. 12. This angle is subtracted from the slenderness angle $\alpha$ to account for the negative influence of the slope (i.e. it favours the occurrence of the lifting and overturning of the construction) leading to the effective slenderness angle $\alpha_{f}$ defined by:

$\alpha_{f}=\alpha-\beta$

The type of foundation connection between the construction and the soil is also accounted for in the analysis. If the construction has a foundation system that can provide some sort of base isolation (e.g. such as the orthostat foundation systems referred in [83] which involve several layers of smoothed stone without mortar between them), the expected level of damage obtained from the analysis can be reduced by one level. However, if the base of the construction sits on top of a surface that can be assumed as rigid with respect to base isolation features or if the base of the construction is buried at a low-depth, no correction of the expected level of damage is needed. Finally, if the base of the construction is buried at a significant depth, the damage analysis is not valid since the behaviour of the construction will be different than assumed by the methodology presented herein.

In the proposed procedure, the expected level of damage depends on slenderness and frequency parameters. The slenderness parameter $\lambda$ is given by:

$\lambda=\frac{1}{\tan \left(\alpha_{f}\right)}$

On the other hand, the frequency parameter $p$ is defined differently for each type of construction [85]. For Type I constructions, parameter $p$ is given by:

$p=\sqrt{\frac{3 \cdot g}{4 \cdot R_{0}}}$

where $g$ is the gravitational acceleration (i.e. $9.81 \mathrm{~m} / \mathrm{s}^{2}$ ) and $R_{0}$ is defined in Fig. 11. For Type II constructions, parameter $p$ is given by:

$p=\sqrt{\frac{3 \cdot g}{4 \cdot R_{0}}} \cdot \sqrt{\frac{16}{3\left(6-\sin ^{2} \alpha\right)}}$
Finally, for Type III constructions, parameter $p$ reflects the stabilising effect of the architrave and is given by:

$p=\sqrt{\frac{3 \cdot g}{4 \cdot R_{0}}} \cdot \sqrt{\frac{1+2 \cdot \zeta}{1+3 \cdot \zeta}}$

Based on the geometric parameters, the material properties, the soil characteristics and the selected seismic hazard scenario, the seismic fragility indexes $\tau_{1}$ and $\tau_{2}$ are then determined to establish the expected level of damage. Index $\tau_{1}$ defines a limit for the ground acceleration up to which a given construction is not expected to develop a rocking mechanism and is obtained by:

$\tau_{1}=\frac{1}{\lambda \cdot S}$

where $S$ is a soil factor accounting for soil amplification effects defined according to Eurocode 8 [101]. Index $\tau_{2}$ establishes a limit for the ground acceleration above which the construction is expected to overturn and collapse and is defined by:

$\tau_{2}=\frac{5}{1.7 \cdot S \cdot p \cdot T_{c}} \cdot \tan \left(\alpha_{f}\right)$

where $T_{c}$ is the period corresponding to the upper limit of the constant acceleration branch of a standard response spectrum. In the current procedure, $T_{C}$ is also defined according to Eurocode 8 [101]. The expected level of damage is then determined by comparing the seismic fragility indexes $\tau_{1}$ and $\tau_{2}$ with the peak ground acceleration $\tau_{d}$ that is expected at the site for the selected seismic hazard scenario. The value of $\tau_{d}$ can be obtained, for example, from earthquake design standards and can be associated with different hazard likelihoods using an appropriate relation with the return period (e.g. see [101]). If $\tau_{d}$ is lower than $\tau_{1}$, the expected level of damage is classified as Light, if $\tau_{d}$ is higher than $\tau_{1}$ but lower than $\tau_{2}$, the expected level of damage is classified as Medium and if $\tau_{d}$ is higher than $\tau_{2}$, the expected level of damage is classified as Heavy. Based on these ranges, Light damage is expected to involve sliding between the several block components without developing a rocking mechanism. For Medium damage the construction is expected to develop a rocking mechanism that will increase the damage between the block components without leading to global overturning. Finally, Heavy damage will correspond to the case where the overturning and collapse of the construction will occur.

\section{Results and discussion: risk analysis of the Roman Temple of Évora}

The results of the simplified seismic risk analysis of the Roman Temple of Évora according to the proposed framework are presented herein. The expected level of damage is determined using the procedure detailed in the previous section and part of the results are then compared with those of an advanced numerical analysis simulating the behaviour of the temple under earthquakes [97]. The selected earthquake scenario corresponds to the earthquake design intensity set by the Portuguese national annex of Eurocode 8 [102] which is considered to be a low likelihood event (i.e. it has an annual probability of occurrence around $0.2 \%$ ). Two types of earthquakes need to be considered for this scenario according to [102]: (i) earthquakes with epicentres mainly offshore termed earthquake type 1 (EQ1) and (ii) earthquakes with epicentres mainly inland termed earthquake type 2 (EQ2). The value of $\tau_{d}$ for the location of the temple is found to be $0.10 \mathrm{~g}$ for EQ1 and $0.11 \mathrm{~g}$ for EQ2 [102] and the value of $\tau_{c}$ is also different for these two types of earthquakes: $0.6 \mathrm{~s}$ for EQ1 and $0.25 \mathrm{~s}$ for EQ2 [101]. Since the columns of the temple sit on top of a plinth which is not expected to be made of solid rock $[97,99]$ and based on the soil mapping for Portugal presented in [102], the foundation soil was considered to be of type B [103] thus leading to a soil factor $S$ equal 
Table 2

Intermediate parameters needed to determine $\tau_{1}$ and $\tau_{2}$.

\begin{tabular}{lllll}
\hline System & $\alpha_{f}=\alpha(\mathrm{rad})$ & $\lambda$ & $\varsigma$ & $p(\mathrm{~Hz})$ \\
\hline 1 & 0.12 & 8.56 & 0.331 & 1.258 \\
2 & 0.12 & 8.56 & 0.252 & 1.275 \\
3 & 0.12 & 8.56 & 0.344 & 1.256 \\
4 & 0.13 & 7.44 & - & 1.475 \\
\hline
\end{tabular}

Table 3

Values of $\tau_{1}$ and $\tau_{2}$ for the EQ1 and EQ2 earthquake types 1 .

\begin{tabular}{llll}
\hline System & $\tau_{1}(\mathrm{~g})$ & $\tau_{2}(\mathrm{EQ} 1)(\mathrm{g})$ & $\tau_{2}(\mathrm{EQ} 2)(\mathrm{g})$ \\
\hline 1 & 0.087 & 0.337 & 0.810 \\
2 & 0.087 & 0.333 & 0.790 \\
3 & 0.087 & 0.338 & 0.811 \\
4 & 0.100 & 0.331 & 0.793 \\
\hline
\end{tabular}

to 1.35 . With respect to the type of foundation system, no base isolation features such as those referred in the previous section were considered.

Given the configurations of Systems 1 to 4 (Fig. 9), it can be seen that Systems 1 to 3 are Type III constructions while System 4 is a Type I construction. The intermediate parameters needed to establish $\tau_{1}$ and $\tau_{2}$ for each system are presented in Table 2 and are based on the survey data found in [97,99]. The values of $\tau_{1}$ and $\tau_{2}$ that were then determined for each earthquake type (EQ1 and EQ2) are presented in Table 3. Since $\tau_{2}$ depends on the value of $\tau_{c}$, different values are obtained for EQ1 and EQ2.

Since $\tau_{1}<\tau_{d}<\tau_{2}$ for Systems 1 to 3 , the considered earthquake scenario is seen to lead to an expected level of damage that is Medium. These three Systems govern the behaviour of the construction for the intensity of the selected earthquake scenario essentially because System 4 is shorter. The values that were obtained for $\tau_{2}$ also lead to two other conclusions: the overturning and collapse of the construction is governed by EQ1 and the earthquake intensity for which it is expected to occur is between three to four times the intensity of the selected scenario. Both conclusions are in agreement with the findings of the advanced numerical simulation studies that were carried out in [97]. Furthermore, the findings in [97] are also in agreement with the expected level of damage that was obtain herein for the earthquake scenario selected for the current analysis.

Based on this level of damage, the next step of the framework analyses the reparability of those damages. Given that for medium damage the construction is expected to develop a rocking mechanism that will cause some physical damage such as sliding and chipping of small pieces of stone, the level of damage is expected to be only partially repairable. Nonetheless, given the type of construction, its function is expected to be easily restored and no significant loss of value is foreseen. Based on these considerations, the vulnerability level of the construction is found to be $V_{\text {II }}$ (Fig. 1). Combining this level of vulnerability with the low likelihood of the selected earthquake scenario leads to a risk level $\mathrm{R}_{\text {III }}$ (Fig. 2).

\section{Final remarks}

The simplified risk assessment framework proposed herein can be used as a screening procedure for the preliminary assessment of a large number of cultural heritage assets with limited resources or for the preliminary identification of assets that require a more refined and resource demanding risk evaluation. The procedure involves a qualitative risk analysis based on a set of structured assessment flowcharts addressing the main components of a risk analysis: the likelihood of the hazard, the consequences of the hazard, the vulnerability and the loss of value of the asset and, finally, the capacity to recover from the event.
The general framework was further detailed by developing specific damage assessment forms and guidelines for the case of seismic risk [71]. In this context, specific procedures were developed to analyse the expected level of damage for four types of cultural heritage masonry constructions. The main aspects of these procedures were described and an illustrative application for the Roman Temple of Évora in Portugal was also presented. Comparable results of this application were found to be in agreement with those of an advanced study simulating the behaviour of the temple under earthquakes. Nonetheless, additional applications should be carried out involving constructions damaged by past earthquakes to validate the proposed methodology.

Further refinements of the proposed framework are expected to be developed in the near future to include more types of constructions as well as to define similar guidelines for other types of hazards.

\section{References}

[1] T. Aven, On how to define, understand and describe risk, Reliability Eng. Syst. Saf 95 (6) (2010) 623-631.

[2] UNISDR Terminology on disaster Risk Reduction. International strategy for disaster reduction, United Nations, Geneva, Switzerland, 2009 [http://www.unisdr.org/we/inform/terminology, last accessed on April 2016].

[3] S. Manyena, The concept of resilience revisited, Disasters 30 (4) (2006) 433-450.

[4] Hyogo Framework for Action 2005-2015: building the resilience of Nations and Communities to Disasters. Extract from the final report of the World Conference on Disaster Reduction (A/CONF.206/6). International strategy for disaster reduction, United Nations, Geneva, Switzerland, 2007 [UN/ISDR-072007].

[5] Sendai framework for disaster risk reduction 2015-2030. United Nations international strategy for disaster reduction, 1st ed., 2015 [UNISDR/GE/2015 - ICLUX EN5000, Geneva, Switzerland].

[6] Synthesis report on consultations on a post-2015 framework on disaster risk reduction (HFA2). International strategy for disaster reduction, United Nations, Geneva, Switzerland, 2013.

[7] The post 2015 Hyogo framework for action: managing risks to achieve resilience. Communication from the Commission to the European Parliament, the Council, the European Economic and Social Committee and the Committee of the Regions, Brussels, Belgium, European Commission, 2014.

[8] K. Ishigaki, J. Mochizuki, Post-2015 framework for disaster risk reduction: a proposal for monitoring progress, 2014,pp.304-307 [GRF Davos Planet@Risk 2(5) Special Issue for the Post-2015 Framework for DRR]

[9] F. Schreiber, Resilient Cities 2014-5th Global Forum on Urban Resilience and Adaptation, 2014, pp. 318-323 [GRF Davos Planet@Risk 2(5) Special Issue for the Post-2015 Framework for DRR].

[10] R. Jigyasu, M. Murthy, G. Boccardi, C. Marrion, D. Douglas, J. King, et al., Heritage and resilience: issues and opportunities for reducing disaster risks. Fourth session of the Global Platform on Disaster Risk Reduction, ICORPICOMOS, UNISDR, UNESCO, ICCROM, 2013.

[11] Heritage at risk: ICOMOS World Report 2008/2010 on monuments and sites in danger, in: C. Machat, M. Petzet, J. Ziesemer (Eds.), International council on monuments and sites, Hendrik Bäßler, 2010.

[12] The Great East Japan earthquake-report on the damage to the cultural heritage, ICOMOS National Committee, Japan, 2011.

[13] R. Kurin, Saving Haiti's heritage - cultural recovery after the earthquake, Smithsonian Institution, 2011.

[14] E. Cunliffe, Damage to the soul: Syria's cultural heritage in conflict, Global Heritage Fund, 2012.

[15] X. Romão, A.A. Costa, E. Paupério, H. Rodrigues, R. Vicente, H. Varum, et al., Field observations and interpretation of the structural performance of constructions after the 11 May 2011 Lorca earthquake, Eng. Fail. Anal 34 (2013) 670-692.

[16] Heritage at risk: world report 2011/2013 on monuments and sites in danger, in: C. Machat, M. Petzet, J. Ziesemer (Eds.), International council on monuments and sites, Hendrik Bäßler, 2014.

[17] D. de la Fuente, J. Vega, F. Viejo, I. Díaz, M. Morcillo, City scale assessment model for air pollution effects on the cultural heritage, Atmos. Environ 456 (2011) 1242-1250

[18] M. Rogerio-Candelera, M. Lazzari, E. Cano (Eds.), Science and technology for the conservation of cultural heritage, CRC Press, 2013.

[19] B. Marzeion, A. Levermann, Loss of cultural world heritage and currently inhabited places to sea-level rise, Environ Res Lett 9 (3) (2014) 034001-034008.

[20] D. D’Ayala, S. Lagomarsino, Performance-based assessment of cultural heritage assets: outcomes of the European FP7 PERPETUATE project, Bull. Earthquake Eng 13 (1) (2015) 5-12. 
[21] G. Lollino, D. Giordan, C. Marunteanu, B. Christaras, I. Yoshinori, C. Margottini (Eds.), Engineering geology for society and territory - volume 8 - preservation of cultural heritage, Springer, 2015.

[22] J. Bommer, Deterministic vs. probabilistic seismic hazard assessment: an exaggerated and obstructive dichotomy, J. Earthquake Eng 6 (S1) (2002) 43-73.

[23] R. Sparks, W. Aspinall, Volcanic activity: frontiers and challenges in forecasting prediction and risk assessment, in: R. Sparks, C. Hawkesworth (Eds.), The state of the planet: frontiers and challenges in geophysics, geophysical monograph 19, IUGG, 2004, pp. 359-373.

[24] S. Lari, P. Frattini, G. Crosta, A probabilistic approach for landslide hazard analysis, Eng. Geol 182 (2014) 3-14 [Part A].

[25] J. Wang, Flood risk maps to cultural heritage: measures and process, J. Cult. Herit 16 (2) (2015) 210-220.

[26] D. Lange, S. Devaney, A. Usmani, An application of the PEER performance based earthquake engineering framework to structures in fire, Eng Struct 66 (2014) 100-115.

[27] S. Kincaid, An investigation into the fire safety management of historic buildings, Sheffield Hallam University Built Environment Research Transactions 4 (1) (2012) 24-37.

[28] K. Smith, Environmental hazards: assessing risk and reducing disaster, Routledge, 2013.

[29] K. Pitilakis, H. Crowley, A. Kaynia, SYNER-G: typology definition and fragility functions for physical elements at seismic risk: buildings, lifelines. Transportation Networks and Critical Facilities, Springer Science \& Business Media, 2014 [Vol. 27].

[30] L. Solín, P. Skubinčan, Flood risk assessment and management: review of concepts, definitions and methods, Geograph. J 65 (1) (2013) 23-44.

[31] D. Hadjimitsis, A. Agapiou, D. Alexakis, A. Sarris, Exploring natural and anthropogenic risk for cultural heritage in Cyprus using remote sensing and GIS, Int. J. Digit. Earth 6 (2) (2013) 115-142

[32] P. Asteris, M. Chronopoulos, C. Chrysostomou, H. Varum, V. Plevris, N. Kyriakides, et al., Seismic vulnerability assessment of historical masonry structural systems, Eng Struct 62-63 (2014) 118-134.

[33] J. Watts Jr., M. Kaplan, Fire Risk Index for historic buildings, Fire Technol 37 (2) (2001) 167-180

[34] T. Goded, J. Irizarry, E. Buforn, Vulnerability and risk analysis of monuments in Málaga city's historical centre (Southern Spain), Bull. Earthquake Eng 10 (3) (2012) 839-861.

[35] A. Blanco-Vogt, J. Schanze, Assessment of the physical flood susceptibility of buildings on a large scale-conceptual and methodological frameworks, Nat. Hazard. Earth. Syst. Sci 14 (2014) 2105-2117.

[36] V. Stephenson, D. D’Ayala, A new approach to flood vulnerability assessment for historic buildings in England, Nat. Hazard. Earth. Syst. Sci. 14 (2014) 1035-1048.

[37] P. Ortiz, V. Antunez, J. Martín, R. Ortiz, M. Vázquez, E. Galán, Approach to environmental risk analysis for the main monuments in a historical city, J. Cult. Herit. 15 (4) (2014) 432-440.

[38] G. Cimellaro, A. Reinhorn, M. Bruneau, Framework for analytical quantification of disaster resilience, Eng. Struct 32 (11) (2010) 3639-3649.

[39] P. Arbon, K. Gebbie, L. Cusack, S. Perera, S. Verdonk, Developing a model and tool to measure community disaster resilience, Torrents Resilience Institute, Adelaide, Australia, 2012.

[40] D. Henry, J. Ramirez-Marquez, Generic metrics and quantitative approaches for system resilience as a function of time, Reliability Eng. Syst. Saf. 99 (2012) $114-122$.

[41] S. Menoni, D. Molinari, D. Parker, F. Ballio, S. Tapsell, Assessing multifaceted vulnerability and resilience in order to design risk-mitigation strategies, Nat. Hazard 64 (3) (2012) 2057-2082.

[42] C. Zobel, L. Khansa, Characterizing multi-event disaster resilience, Comput. Oper. Res. 42 (2014) 83-94.

[43] B. Ayyub, Systems resilience for multihazard environments: definition, metrics, and valuation for decision-making, Risk Anal 34 (2) (2014) 340-355.

[44] C. Zobel, Quantitatively representing nonlinear disaster recovery, Decis. Sci 45 (6) (2014) 1053-1082.

[45] M. De la Torre (Ed.), Assessing the value of cultural heritage. Research Report, The Getty Conservation Institute, Los Angeles, 2002.

[46] K. Vecvagars, Valuing damage and losses in cultural assets after a disaster: concept paper and research options. CEPAL - SERIE Estudios y perspectivas-Sede Subregional de la CEPAL en México, United Nations Publication, 2006

[47] P. Nijkamp, Chapter 4 - economic valuation of cultural heritage. The economics of uniqueness: investing, in: G. Licciardi, R. Amirtahmasebi (Eds.), Historic city cores and cultural heritage assets for sustainable development, World Bank Publications, 2012.

[48] DassanayakeF D., A. Burzel, H. Oumeraci, Evaluation of cultural losses. XtremRisK Progress Report, Leichtweiß-Institute for Hydraulic Engineering and Water Resources, Technische Universität Braunschweig, 2012.

[49] L. Cox, D. Babayev, W. Huber, Some limitations of qualitative risk rating systems, Risk Anal 25 (3) (2005) 651-662.

[50] M. Rausand, Risk assessment: theory, methods, and applications, John Wiley \& Sons, 2013.

[51] J. Lund, A risk analysis of risk analysis, J. Contemp. Water Res. Educ 140 (1) (2008) 53-60.

[52] S. Krings, Verwundbarkeitsassessment der Strom- und Trinkwasserversorgung gegenüber Hochwasserereignissen, in: J. Birkmann, S. Dech, M.
Gähler, S. Krings, W. Kühling, K. Meisel, A. Roth, A. Schieritz, H. Taubenböck, M. Vollmer, T. Welle, J. Wolfertz, Wurm M., Zwenzner H. (Eds.), Abschätzung der Verwundbarkeit gegenüber Hochwasserereignissen auf kommunaler Ebene, Federal Office of Civil Protection and Disaster Assistance, Bonn, 2010.

[53] J. Birkmann, C. Bach, M. Vollmer, Tools for resilience building and adaptive spatial governance, Raumforschung und Raumordnung 70 (4) (2012) 293-308.

[54] R. Cooke, L. Goossens, Expert judgement elicitation for risk assessments of critical infrastructures, J. Risk Res 7 (6) (2004) 643-656.

[55] A. Babuscia, K. Cheung, An approach to perform expert elicitation for engineering design risk analysis: methodology and experimental results, J. R. Stat. Soc 177 (2) (2014) 475-497.

[56] M. Catenacci, V. Bosetti, G. Fiorese, E. Verdolini, Expert judgment elicitation protocols, in: V. Bosetti, M. Catenacci (Eds.), Innovation under uncertainty: the future of carbon-free energy technologies, Edward Elgar Publishing, 2015.

[57] A. Copping, The development of a fire safety evaluation procedure for the property protection of parish churches, Fire Technol 38 (4) (2002) 319-334.

[58] R. De Risi, F. Jalayer, F. De Paola, I. Iervolino, M. Giugni, M. Topa, et al., Flood risk assessment for informal settlements, Nat. Hazard 69 (1) (2013) 1003-1032.

[59] S. Giovinazzi, The vulnerability assessment and the damage scenario in seismic risk analysis, Technical University Carolo-Wilhelmina at Braunschweig and Faculty of Engineering of the University of Florence, 2005 [PhD Dissertation].

[60] A. Godfrey, R. Ciurean, C. van Westen, N. Kingma, T. Glade, Assessing vulnerability of buildings to hydro-meteorological hazards using an expert based approach-an application in Nehoiu Valley, Romania, Int. J. Disaster Risk Reduction 13 (2015) 229-241.

[61] M. Ibrahim, K. Abdul Hamid, M. Ibrahim, A. Mohd Din, R. Mohd Yunus, M. Yahya, The development of fire risk assessment method for heritage building, Procedia Eng 20 (2011) 317-324.

[62] F. Jalayer, S. Carozza, R. De Risi, G. Manfredi, E. Mbuya, Performance-based flood safety-checking for non-engineered masonry structures, Eng. Struct 106 (2016) 109-123.

[63] M. Kappes, M. Papathoma-Köhle, M. Keiler, Assessing physical vulnerability for multi-hazards using an indicator-based methodology, Appl. Geogr 32 (2) (2012) 577-590.

[64] Z. Li, F. Nadim, H. Huang, M. Uzielli, S. Lacasse, Quantitative vulnerability estimation for scenario-based landslide hazards, Landslides 7 (2)(2010)125-134.

[65] A. Mebarki, N. Valencia, J. Salagnac, B. Barroca, Flood hazards and masonry constructions: a probabilistic framework for damage, risk and resilience at urban scale, Nat. Hazard. Earth Syst. Sci 12 (5) (2012) 1799-1809.

[66] A. Puissant, M. Van Den Eeckhaut, M. Kappes, M. Papathoma-Koehle, M. Keiler, J. Hervás, et al., Index-oriented methodologies for landslide consequence analysis: an application to a mountain community in the French Alps, in: Landslide science and practice, Springer, Berlin Heidelberg, 2013, pp. 159-167.

[67] R. Spence, I. Kelman, An overview of flood actions on buildings, Eng. Geol 73 (3) (2004) 297-309

[68] V. Stephenson, D. D’Ayala, A new approach to flood vulnerability assessment for historic buildings in England, Nat. Hazard. Earth. Syst. Sci 14 (5) (2014) 1035-1048

[69] R. Vicente, Strategies and methodologies for urban rehabilitation interventions: vulnerability assessment and seismic risk of the buildings of the downtown of Coimbra, University of Aveiro, 2008 [PhD Dissertation].

[70] J. Watts Jr., Fire risk indexing, in: SFPE handbook of fire protection engineering, Springer, New York, 2016, pp. 3158-3182.

[71] X. Romão, E. Paupério, N. Pereira, Methodology for the rapid evaluation of seismic risk in immovable cultural. Report for the National Authority for Civil Protection, Construction Institute and Faculty of Engineering, University of Porto, Porto, 2015 [in Portuguese].

[72] Conservation principles - policies and guidance for the sustainable management of the historic environment. English Heritage, 2008.

[73] S. Lagomarsino, S. Cattari, PERPETUATE guidelines for seismic performancebased assessment of cultural heritage masonry structures, Bull. Earthquake Eng 13 (1) (2015) 13-47.

[74] S. Lagomarsino, On the vulnerability assessment of monumental buildings, Bull Earthquake Eng 4 (4) (2006) 445-463.

[75] P. Lourenço, D. Oliveira, J. Leite, J. Ingham, C. Modena, F. da Porto, Simplified indexes for the seismic assessment of masonry buildings: international database and validation, Eng. Fail. Anal 34 (2013) 585-605.

[76] S. Pereira, Análise de critérios simplificados para a avaliação de vulnerabilidade sísmica de igrejas, Faculty of Engineering of the University of Porto, 2013 [MSc Dissertation. In Portuguese].

[77] A. Simões, J. Milošević, H. Meireles, R. Bento, S. Cattari, S. Lagomarsino, Fragility curves for old masonry building types in Lisbon, Bull. Earthquake Eng 13 (10) (2015) 3083-3105.

[78] E. Curti, Vulnerabilità sismica delle torri Campanarie: modelli meccanici e Macrosismici, Università degli Studi di Genova, 2007 [PhD Dissertation. In Italian].

[79] V.Sepe, E. Speranza, A. Viskovic, A method for large-scale vulnerability assessment of historic towers, Struct Control Health Monit 15 (3) (2008) 389-415.

[80] S. Casciati, L. Faravelli, Vulnerability assessment for medieval civic towers, Struct. Infrastruct. Eng 6 (1-2) (2010) 193-203.

[81] M. Shakya, H. Varum, R. Vicente, A. Costa, A new methodology for vulnerability assessment of slender masonry structures. Second European Conference on Earthquake Engineering \& Seismology, 2014 [Istanbul, Turkey]. 
[82] Y. Ishiyama, Motions of rigid bodies and criteria for overturning by earthquake excitations, Earthquake Eng. Struct. Dyn 10 (5) (1982) 635-650.

[83] A. Bayraktar, H. Keypour, A. Naderzadeh, Application of ancient earthquake resistant method in modern construction technology, in: 15th World Conference on Earthquake Engineering, Lisbon, Portugal, 2012.

[84] E. Dimitrakopoulos, M. DeJong, Revisiting the rocking block: closed-form solutions and similarity laws, Proc. R. Soc. Lond. A 468 (2144) (2012) 2294-2318.

[85] M. DeJong, E. Dimitrakopoulos, Dynamically equivalent rocking structures, Earthquake Eng. Struct. Dyn 43 (10) (2014) 1543-1563.

[86] E. Dimitrakopoulos, T. Paraskeva, Dimensionless fragility curves for rocking response to near-fault excitations, Earthquake Eng. Struct. Dyn 44 (12) (2015) 2015-2033.

[87] S. Lagomarsino, Seismic assessment of rocking masonry structures, Bull. Earthquake Eng 13 (1) (2015) 97-128.

[88] A. Pappas, Structural analysis and modelling approaches for the seismic vulnerability assessment of archaeological ruins, Università degli Studi di Padova, 2015 [PhD Dissertation].

[89] D. Oliveira, P. Lourenço, C. Lemos, Geometric issues and ultimate load capacity of masonry arch bridges from the northwest Iberian Peninsula, Eng. Struct 32 (2010) 3955-3965.

[90] G. Tecchio, P. Zampieri, F. da Porto, C. Modena, A. Prota, G. Manfredi, Simplified assessment of railway masonry bridges seismic capacity, in: 15th World Conference on Earthquake Engineering, Lisbon, Portugal, 2012.

[91] P. Zampieri, G. Tecchio, F. da Porto, C. Modena, Limit analysis for transverse seismic capacity of multi-span masonry arch bridges, Bull. Earthquake Eng 13 (5) (2015) 1557-1579.

[92] F. da Porto, G. Tecchio, P. Zampieri, C. Modena, A. Prota, Simplified seismic assessment of railway masonry arch bridges by limit analysis, Struct. Infrastruct. Eng 12 (5) (2016) 567-591.

[93] Roman Temple at Evora, Portugal. Wikimedia Commons, the free media repository, 2007 [https://commons.wikimedia.org/wiki/File:EvoraRomanTemple.jpg, last accessed on April 2016].
[94] Templo Romano de Évora, Direção-Geral do Património Cultural. Ministério da Cultura, 2015 [http://www.patrimoniocultural.pt/pt/patrimonio/ patrimonio-imovel/pesquisa-do-patrimonio/classificado-ou-em-viasde-classificacao/geral/view/70489, last accessed on April 2016, in Portuguese].

[95] L. Lopes, J. Lopes, J. Cabral, P. Sarantopoulos, Caracterização Petrográfica dos Monumentos Romanos de Évora. A cidade de Évora II(4), 2000, pp. 129-142 [in Portuguese].

[96] D. Oliveira, G. Grecchi, A. McCall, J. Noh, E. Speer, M. Tohidi, Seismic analysis of the Roman Temple of Évora, Portugal, in: 15th World Conference on Earthquake Engineering, Lisbon, Portugal, 2012.

[97] S. Nayeri, Seismic assessment of the Roman temple in Évora, Portugal, University of Minho, 2012 [MSc Dissertation, Advanced Masters in Structural Analysis of Monuments and Historical Constructions].

[98] D. Oliveira, S. Nayeri, J. Lemos, R. Alfenim, P. Lourenço, Análise sísmica do Templo Romano de Évora. 5as Jornadas Portuguesas de Engenharia de Estruturas, Lisbon, Portugal, 2014 [in Portuguese].

[99] G. Grecchi, A. McCall, J. Noh, E. Speer, M. Tohidi, The Roman Temple in Évora: a conservation proposal. SA7 - integrated project report, advanced masters in structural analysis of monuments and historical constructions, University of Minho, 2012.

[100] I. Psycharis, J. Lemos, D. Papastamatiou, C. Zambas, C. Papantonopoulos, Numerical study of the seismic behaviour of a part of the Parthenon Pronaos, Earthquake Eng. Struct. Dyn 32 (13) (2003) 2063-2084

[101] ENV 1998-1. Eurocode 8: design of structures for earthquake resistance - part 1: general rules, seismic actions and rules for buildings, European Committee for Standardization, Brussels, Belgium, 2004.

102] NP ENV 1998-1. Portuguese National Annex to Eurocode 8: design of structures for earthquake resistance - part 1: general rules, seismic actions and rules for buildings, Instituto Português da Qualidade, Lisbon, Portugal, 2010

[103] V. Silva, Development of open models and tools for seismic risk assessment: application to Portugal, University of Aveiro, 2013 [PhD Dissertation]. 